\title{
las resinas epoxi en la construckión
}

M. FERNANDEZ CANOVAS

\section{simepesis}

Hoy viene hasta nosotros un nuevo producto, lleno de posibilidades dentro del campo de la construcción. Las RESINAS EPOXI: Sus aplicaciones, éxitos en la mayoría de los casos, según las referencias, obliga a abordar este tema en toda su amplitud.

Sin embargo, en el presente artículo sólo se pretende hacer una breve exposición de lo que son estas resinas, hacién. dose una pequeña historia de su descubrimiento y aplicaciones en los diversos campos de la técnica. Se indican algunas de sus propiedades, características y métodos de preparación, dedicándose especial atención a sus usos en morteros, juntas de hormigonado, etc. También se da cuenta de los trabajos de ensayo e investigación que se están llevando a cabo en el Instituto Eduardo Torroja.

La técnica, en su constante inquietud superadora, hoy nos trae un nuevo producto llamado a solucionar muchos de los problemas que en las aplicaciones del hormigón eran insolubles, e incluso, cuando se lograba resolverlos, la garantía era tan dudosa que no desaparecía de nosotros la sombra de la intranquilidad ante un probable accidente. Hoy, gracias a la cada vez más desarrollada aplicación de las resinas epoxi, podemos estar tranquilos ante los favorables resultados que se han obtenido. Por otra parte, las resinas han dado lugar a la aparición de nuevos conglomerados, tales como morteros, etc.

Las resinas epoxi han experimentado un rápido desarrollo en los Estados Unidos, donde fueron introducidas en el campo de la construcción hacia el año 1949. Este desenvolvimiento tan rápido ha sido debido a sus excelentes propiedades, entre las que podemos citar: su rápido endurecimiento a la temperatura normal, pasando del estado líquido al sólido; un alto grado de adherencia a muchas superficies; gran tenacidad con excelente durabilidad; gran resistencia a rotura, y una gran resistencia química frente a la acción de ácidos, álcalis y disolventes.

El empleo de las resinas epoxi se inició aplicándolas a la fabricación de pinturas y a la unión de elementos estructurales en la industria aeronáutica. Rápidamente su uso fue extendiéndose y evolucionando, pero fue precisamente en 1955 cuando estas resinas entraron de lleno en el campo de la construcción, y en especial, en el de las carreteras. 
Desde entonces, las aplicaciones han ido progresando, y hoy día son innumerables. Podemos citar, a este fin, las aplicaciones siguientes:

componentes de bacheo;

selladores de juntas y grietas;

membranas impermeabilizantes;

preparación de superficies resistentes al deslizamiento y desgaste en pisos de hormigón; adhesivos para unión de hormigón fresco a hormigón endurecido;

adhesivos para unir acero, bronce, latón u otros materiales a hormigón;

agentes de enlucido;

pinturas para marcar señales de tráfico;

pinturas resistentes a la corrosión aplicándolas a la superficie de hormigón para prevenir ataque químico, etc.

Como se ve, estas resinas han hecho posible resolver muchos de los problemas que se presentaban en carreteras, pistas de aterrizaje, etc., al mismo tiempo que en obras de hormigón vienen a solucionar los delicados problemas que surgían en las uniones de hormigones de distinta edad, así como en aquellas averías de obras que han de ser rápidamente reparadas.

En España tenemos noticias de aplicaciones de las resinas epoxi en el bacheado de algunas pistas, así como la reparación de averías en conducciones de suministro de agua potable a ciudades, etc., siendo muy satisfactorios los resultados obtenidos.

Las resinas epoxi no se emplean aisladamente en construcción, sino formando mezclas con otros componentes, normalmente agentes de endurecimiento, flexibilizadores y, en ocasiones, acelerantes. No hay que olvidar que las resinas puras poseen poca flexibilidad, particularmente en tiempo frío. Cada componente es estable independientemente, pero una vez mezclados se produce una reacción química exotérmica que transforma la mezcla líquida en una sólida plástica, siendo el tiempo de transformación dependiente de la temperatura, y en el sentido de que el calor acelera el proceso de endurecimiento.

En general, a la temperatura ambiente la transformación es bastante rápida, pudiendo estimarse que para una temperatura de $25^{\circ} \mathrm{C}$ el tiempo de aplicación es de 45 minutos, pasados los cuales las condiciones de pegado son casi nulas. Para una temperatura de $45^{\circ} \mathrm{C}$ este tiempo se reduce a 30 minutos, y para temperaturas de 65 y $70^{\circ} \mathrm{C}$, normales en climas desérticos, el tiempo de aplicación decrece hasta valores insignificantes que llegan hasta 5 minutos. Por el contrario, en climas fríos este tiempo aumenta mucho, y entonces, para conseguir endurecimientos más rápidos, hay que recurrir a calentamientos; así, en el caso de bacheado de carreteras en tiempo frío se recurre a cubrir el parche con una plancha de acero que se calienta con soplete, pudiendo, por este procedimiento, conseguir abrir la carretera al tránsito en un plazo de hasta dos horas.

Para unión de hormigones de distinta edad, que es una de las aplicaciones de más éxito de estas resinas, así como para el bacheo de carreteras y pistas de aviación, se hace imprescindible que la superficie a tratar se encuentre perfectamente seca y limpia de polvo, aceite, grasas o cualquier otra sustancia perjudicial; asimismo esta superficie debe ser sana y dura.

Para la reparación de pequeños baches, el sellado se hace aplicando la resina por vertido, o bien, con cepillo.

Si los baches son de dimensiones mayores, es conveniente hacer un mortero con el adhesivo y arena fina, seca y limpia; la relación conveniente de resina/arena parece ser la de $1 / 7$ en peso, cuando aquélla es fina. La economía que se obtendría empleando arena gruesa parece ser que no es muy grande. no obstante, para baches de grandes dimensiones pueden emplearse ambos tamaños de áridos, llegándose a relaciones en peso de resina/arena de 1/18.

La mezcla puede hacerse a mano, o bien, en máquina. Es muy conveniente el tratar previamente con adhesivo la superficie de unión.

La unión de hormigones de distinta edad se consigue tratando la superficie del hormigón más viejo con resina, y añadiendo el nuevo hormigón lo más rápidamente posible y antes de que la capa de resina haya perdido su poder adherente.

El hormigón nuevo deberá tener una consistencia seca, rechazándose cuando su asiento en el cono de Abrams sea superior a 5 centímetros.

El tratamiento de la superficie puede hacerse pulverizando el adhesivo sobre la misma, si bien para lograr la pulverización es necesario mezclar el adhesivo con un disolvente adecuado, ya que la resina normal es demasiado viscosa para aplicarla de esta forma. En este caso se impone una vigilancia muy rígida sobre todo el proceso y se cuidará no añadir el nuevo hormigón hasta cerciorarse que el disolvente se ha evaporado, ya que, si no, es difícil garantizar el éxito.

Las resinas epoxi presentan también un amplio campo de aplicación en la confección de morteros. En éstos, se sustituye el cemento y el agua por la resina. Las propiedades, como las de los morteros de cemento, varían considerablemente según los materiales empleados, proporción de los componentes y tratamientos de curado. 
Los principales factores que afectan a las propiedades de los morteros podemos resumirlos en:

tipo de resina;

cantidad de resina empleada;

tamaño y granulometría de los áridos;

temperatura y condiciones de curado.

No hay que olvidar que en un mortero epoxi la granulometría influye decisivamente en su composición, ya que las fracciones finas retienen gran cantidad de resina; de aquí el interés por la confección de morteros pobres, en los que se eliminen los finos, llegándose así a relaciones árido/resina muy elevadas, lo que repercute favorablemente en el costo de los mismos. Otras de las ventajas de estos morteros es su buena resistencia mecánica a pesar de su ligereza.

En la actualidad se están realizando, en el Instituto Eduardo Torroja, ensayos sobre el comportamiento de morteros fabricados con resinas epoxi y sobre uniones en las que intervienen dichas resinas como adhesivos. El programa de ensayos es bastante extenso y ya se están sacando conclusiones muy satisfactorias.

Con respecto al empleo de la resina como conglomerante para morteros, se están haciendo ensayos para determinar la resistencia mecánica en función de la granulometría, cantidad y edad de resina, etc. Asimismo, se está estudiando la absorción, succión capilar, durabilidad, peso específico, aislamiento térmico, módulo de elasticidad, etc.

En lo referente a ensayos de adherencia, también se están realizando pruebas para ver la influencia de la dosificación, edad, tratamientos superficiales, etc., de los hormigones y morteros.

Los ensayos que se han efectuado con morteros indican el gran poder adherente de estas resinas, ya que las roturas de las probetas tuvieron lugar por planos distintos a los de pegado, según puede apreciarse en la fotografía que se acompaña de una probeta de tracción.

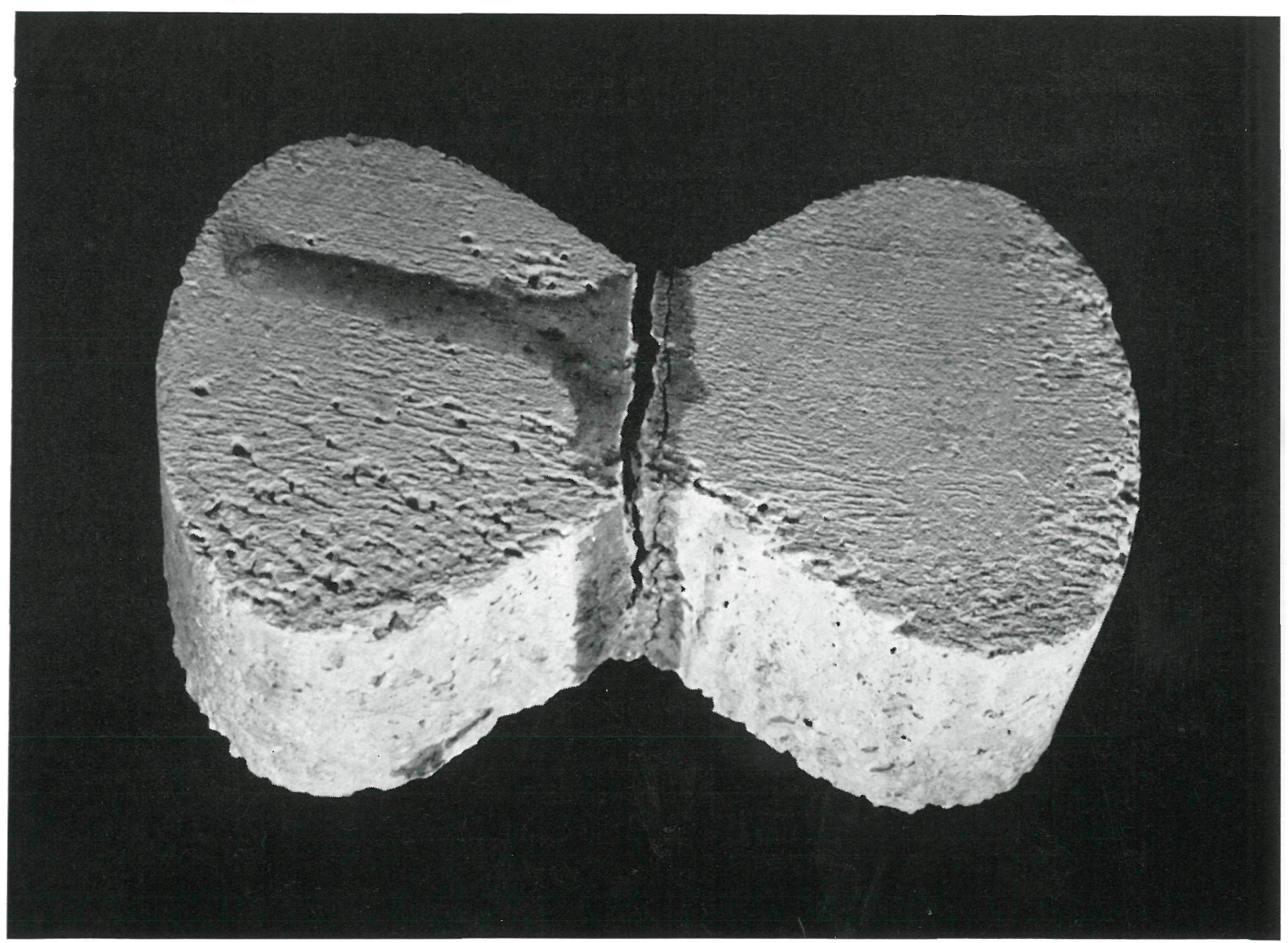




\section{Les mésines Epori dans la constructurion}

M. Fernández Cánovas

Un nouveau produit, plein de possibilités dans le domaine de la construction, s'offre à nous aujourd'hui: les résines EPOXI. Leurs applications, selon les références, en majeure partie pleines de succès, nous obligent à aborder ce thème dans toute son ampleur.

Cependant, cet article ne prétend faire qu'un bref exposé de ce que sont ces résines, relatant l'histoire de leur découverte et de leur application dans les différentes domaines de la technique. Il indique également quelquesunes de leurs propriétés, caractéristiques et méthodes de préparation, attirant tout spécialement l'attention sur leurs applications pour les mortiers, joints de bétonnage, etc. Il rend compte également des travaux d'essais et de recherches actuellement en cours à l'Ins titut Eduardo Torroja.

\section{Epoxi ressins in comstrmetriom}

M. Fernández Cánovas

A new product, full of possibilites in the field of construction, has now become generally available. This is the group of Epoxi Resins. Most of its applications have proved highly successful, and this makes it essential to study this material in all its aspects.

However, in this article only a brief account of the nature of these resins is intented. A history of the discovery is given, and also of its applications to various fields of technology. The article mentions some of the properties of this material, its mode of preparation, and special attention is given to its use in conjuction with mortars, concrete joints, etc. Finally, some information is cited on the tests and research work now being carried out at the Instituto Eduardo Torroja on these resins.

\section{Eporg-Hanze im Barmestem}

M. Fernández Cánovas

Mit den Epoxyharzen haben wir ein neues Produkt vor uns, das für die Anwendung in der Bauindustrie ungeahnte Möglichkeiten bietet. Die in den meisten Fällen damit schon erzielten Erfolge zwingen uns, dieses Thema in all seinen Aspekten zu untersuchen.

In dem vorliegenden Artikel wollen wir allerdings nur eine kurze Ausführung über die Natur der Epoxyharze, die Geschichte ihrer Entdeckung und ihre Anwendung in den verschiedensten Bereichen der Technik geben. Es werden einige ihrer Haupteigenschaften und das Verfahren zu ihrer Herstellung genannt, wobei besonderer Wert auf ihre Anwendung für Mörtel, Betonfugen, etc. gelegt wird.

Ausserdem werden einige Forschungsversuche beschrieben, die zur Zeit im Instituto Eduardo Torroja durchgeführt werden. 